\title{
ARCHITECTURE AND FUNCTION OF LOWER DEVONIAN SPATHOGNATHODID APPARATUSES
}

WEDDIGE*, Karsten, Forschungsinstitut Senckenberg, Senckenberganlage 25, D-60325 Frankfurt am Main, FR Germany; and HUESKEN, Thomas-Christian, Geological Institute of University, Bundestr. 55, D-20146 Hamburg, FR Germany

Among 250 groups of conodont elements, recently discovered on bedding planes of the German upper Lochkovian graptolite alum shales, about 30 demonstrate rather regular arrangements of elements resulting from the collapse and compaction of the originally three-dimensional apparatuses. The groups, as analyzed so far, permit the following conclusions concerning the architecture of the spathognathodid apparatuses at hand: (1) The $\mathrm{Pa}$ and $\mathrm{Pb}$ pair functioned like a right-handed scissor which cuts by a sinistral relative movement of both blades, i.e. the blade from the left side of a pair in counter position overlaps that from the right side. (2) Inner (concave) flank of $\mathrm{a} \mathrm{Pa}$ or a $\mathrm{Pb}$ element, like the left-hand forms of $\mathrm{Pa}$ or $\mathrm{Pb}$ pairs indicate the proximal side of an apparatus. Analogously, the other (convex) element flank and right-hand forms as well indicate the distal apparatus side. (3) In accordance with previous results the transversal order within the "basket" of ramiform elements is M-Sc-Sc-Sb-(Sb)-Sa-(Sb)-Sb-Sc-Sc-M. Inner (concave) flanks of $\mathrm{Sb}$ or Sc elements point to median symmetry axis of the apparatus and outer (convex) element sides point towards the outer lateral sides. Sb and Sc elements of the apparatus appear to differentiate a left and a right (jaw?) arc. Denticles of their medial elements, however, are obliquely inclined against one another so that their tips interfinger. Usually, $\mathrm{M}$ elements lie apart from and more or less obliquely to the array of S elements, but in connection with the median Sa element, the three elements form a triangular ring.

This reconstruction subdivides the three-dimensional "basket" in the following "spaces" (in dorsal view):

...Axially: the "textural space" with interfingering Sb elements.

...Marginally: the "marginal space" with tightly parallel Sc elements forming a subcircular area of erect denticles anteriorly and lateral walls posteriorly.

...Towards the distal end of the basket is steeper than the plane of the marginal space: the "coronal space" the denticles of which point more-or-less towards the front.

If this reconstruction is taken for a basket with fixed elements during feeding than a model of a well functioning sieve apparatus is the result. 